ISNN 1927-9434

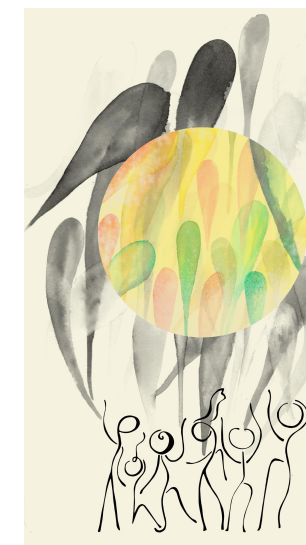

\title{
A fumaça digital: inversão infraestrutural do COVID-19 pela perspectiva Yanomami
}

\author{
Pelanda, Mateus Filipe de Lima \\ Mestrando no Programa de Pós-Graduação em Tecnologia e Sociedade, Universidade \\ Tecnológica Federal do Paraná (PPGTE - UTFPR) \\ mateuspelanda@alunos.utfpr.edu.br \\ van Amstel, Frederick M.C. \\ Departamento Acadêmico de Desenho Industrial, Universidade Tecnológica Federal do Paraná \\ (DADIN - UTFPR) \\ vanamstel@utfpr.edu.br
}

Recebido Mayo 29, 2020, Revisado Janeiro 19, 2021

Aceite Fevereiro 18, 2021, Publicado Março 5, 2021

Como fazer referência a este artigo: Pelanda, M. F. L., \& van Amstel, F. M.C. (2021). A fumaça digital: inversão infraestrutural do COVID-19 pela perspectiva Yanomami. International Journal of Engineering, Social Justice and Peace, v. 8, n. 1, p. 61-77, https://doi.org/10.24908/ijesjp.v8i1.14735

Este ensaio busca, através da aproximação do perspectivismo ameríndio e o campo transdisciplinar de Ciência, Tecnologia e Sociedade (CTS), contextualizar a pandemia do COVID-19 no Brasil sob um viés de responsabilidade. Para tal reflexão, o presente trabalho utiliza como base o termo metodológico inversão infraestrutural, que aponta para um processo de visibilização do trabalho invisível. Em seguida, esses termos são confrontados pelo método de equivocação controlada com os conceitos de Omama, Urihi-a, Hutukara e Xawara, que fazem parte do xamanismo Yanomami. O resultado dessa equivocação é utilizado para reconstruir a narrativa da pandemia a partir da revelação de relações ecológicas e históricas que se encontravam até então invisibilizadas. Destaca-se o papel da fumaça digital em ocultar essas relações recém reveladas. Propõe-se, a partir desta experiência, caminhos futuros para um método 
de equivocação infraestrutural em CTS que revele diferenças entre cosmovisões e projetos existenciais implicados e ameaçados por sistemas sociotécnicos.

\section{Palabras clave:}

Infraestrutura de Informação, Inversão infraestrutural, Xamanismo Yanomami, Perspectivismo ameríndio, Fake new

\section{INTRODUÇÃO}

De acordo com o xamã Yanomami Davi Kopenawa (2019), a civilização ocidental somente esteve preocupada com o presente e, agora, com os desastres naturais provocados pelo homem, o céu estaria caindo sobre as nossas cabeças (Kopenawa \& Albert, 2019). O alerta Yanomami foi recebido pelos ocidentais como uma mera metáfora até a deflagração da pandemia COVID-19, situação em que os sistemas sociotécnicos da civilização dita moderna falharam (Latour, 2020; Santos, 2020). Essa falha pode ser atribuída, em partes, à falta de visão global do fenômeno e das relações diversas que estavam em jogo (Latour, 2020). O campo de estudos de Ciência, Tecnologia e Sociedade (CTS), também já chamava a atenção para a fragilidade instaurada pela invisibilização das relações entre sociedade e ambiente ${ }^{1}$, porém, a denúncia não foi suficiente para prevenir a queda do céu ${ }^{2}$.

Em CTS, destacam-se os conceitos de infraestrutura (Kling \& Scacchi, 1982), infraestrutura de informação (Star \& Ruhleder, 1996) e de inversão infraestrutural (Bowker, 1994) como ferramentas potenciais para auxiliar na compreensão dos problemas que ocorreram durante a pandemia COVID-19. Porém, por partirem das mesmas ontologias responsáveis pela queda do céu, esses conceitos correm o risco de não tornarem suficientemente visíveis os impactos sócio-ambientais do pensamento moderno sobre o mundo. Por isso, buscamos confrontar o pensamento objetivo moderno expresso em $\mathrm{CTS}^{3}$ com o perspectivismo ameríndio.

Este último coloca em questão a produção do mundo, através de um modelo de alteridade radical que forma saberes pela personificação do outro (Viveiros de Castro, 1996). Arturo Escobar expressa o perspectivismo através do conceito de pluriverso: “existem vários mundos reais, mas não se pretende 'corrigir' a visão de um único real com o fundamento de ser uma descrição mais

\footnotetext{
${ }^{1}$ Por exemplo, a questão ambiental marca a tradição norte-americana dos estudos CTS, em estudos como Primavera Silenciosa, de Rachel Carson (1962) ou as reivindicações sobre a opinião pública na construção e utilização de energia nuclear (ver Cutcliffe, 2003).

${ }^{2}$ No livro "Queda do céu: Palavras de um xamã yanomami” (Kopenawa \& Albert, 2019), Kopenawa descreve que, pela concepção Yanomami, no começo do mundo, parte do céu já havia caído sobre a cabeça das pessoas e dizimado grande parte da população. A fim de manter o céu sobre nossas cabeças, parte dos rituais realizados pelos xamãs Yanomami são realizados para que isso não aconteça novamente (Kopenawa \& Albert, 2019).

${ }^{3}$ Como moderno, nos referimos ao paradigma estabelecido pelo pensamento abissal oriundo do Norte global, que fundamenta um sistema de distinções radicais entre o que é visível (existente) e o invisível (inexistente), na forma de pensar e ver o mundo (ver Santos, 2007).
} 
verdadeira da "realidade" (Escobar, 2016c, p. 22). Em cada mundo, há formas completamente únicas e individuais de produzir existências e projetar mundos ${ }^{4}$. Porém, apesar de serem diversas, ainda assim podem contribuir cada uma a sua maneira para a construção de um mundo concreto e compartilhado, "um mundo em que caibam vários mundos" (Escobar, 2016b). O desafio da construção do pluriverso depende da articulação de diferentes cosmovisões (Lagrou, 2020).

Segundo essa linha pluriversal de pensamento, quando o céu está ficando muito baixo, poderíamos juntar esforços para empurrá-lo de volta para cima. O líder indígena Ailton Krenak afirma que tal esforço permitirá que respiremos novamente, ampliando nosso horizonte existencial e aumentando nosso senso de responsabilidade por ser parte do mundo (Krenak, 2019). Este ensaio busca, através da aproximação do pensamento ameríndio e o campo transdisciplinar CTS, contextualizar a pandemia do covid-19 no Brasil sob um viés de responsabilidade. Para iniciar esta reflexão, a próxima seção, Relações ecológicas e invisíveis, fundamenta e desenvolve o conceito de infraestrutura e infraestruturas da informação a partir de uma abordagem CTS.

\section{RELAÇÕES ECOLÓGICAS E INVISÍVEIS}

$\mathrm{Na}$ linguagem coloquial, o termo infraestrutura é utilizado para se referir aos elementos construtivos internos, não aparentes ou invisíveis que servem de base e sustentação para algum edifício. Na linguagem formal de CTS, a palavra infraestrutura está associada aos sistemas sociotécnicos de larga escala (e.g. redes de energia elétrica e de telecomunicação, redes fluviais, sistemas de transporte e entre outras); aos sistemas de serviços básicos, para a realização de outras tarefas; e ao trabalho realizado por outras pessoas para a construção, manutenção e o funcionamento desses sistemas. Em resumo, as infraestruturas podem ser definidas como o entrelaçamento ecológico entre diferentes tecnologias e o trabalho humano, operando no pano de fundo das ações cotidianas (Star \& Ruhleder, 1996). Tais infraestruturas aparecem apenas como uma propriedade relacional, pois o que é infraestrutura para alguns, é trabalho diário para outros (Star, 1999).

Por exemplo, quando se utiliza um transporte público, tal como um ônibus, não é perceptível a quantidade de relações infraestruturais, para que seja possível ir do ponto A ao ponto B. É necessário, ao menos, uma pessoa para dirigir o ônibus; um sistema para cobrança da passagem; o ônibus em si; os assentos para pessoas passageiras; as peças para fazer o motor funcionar; alguém para fazer a manutenção do veículo; a existência de uma rodovia; sinais de trânsito; fiscalização; e uma lista infindável de coisas e prestação de serviços necessários para que tal transporte público exista e funcione. Para o passageiro ou a passageira, se nada de errado acontecer, basta entrar no ônibus, pagar a passagem e esperar a chegada ao destino final.

\footnotetext{
${ }^{4} \mathrm{O}$ termo "projeto" é utilizado neste contexto tal como na pluralidade contida na palavra " diseño", conforme Arturo Escobar descreve em "Autonomía y diseño" (2016a)
} 
Enquanto isso, o restante da infraestrutura continua existindo, mas invisível para esta pessoa. Já para quem dirige ou para quem mantém o veículo, a infraestrutura não é somente aparente, pois essas pessoas também são parte da infraestrutura. Dessa forma, tanto quem trabalha, quanto o próprio trabalho realizado são invisibilizados quando se tornam meios para a realização de outra atividade (Star \& Bowker, 1995).

A invisibilização do trabalho é mais aguda no caso de infraestruturas de informação - instalações e serviços associados ao meio digital, em especial à internet (Bowker et al., 2009). Elas transformam palavras, categorias e procedimentos em ferramentas para gerar e manipular conhecimento abstraído dos conhecedores (Star \& Bowker, 1995).

Infraestruturas de informação são instaladas, criadas e inovadas em relação às infraestruturas de base, restringindo e permitindo a formação de novas infraestruturas (Star, 1999), que herdam os pontos fortes e as limitações das bases sobre as quais foram construídas (Star \& Ruhleder, 1996). Por exemplo, quando uma pessoa pede um sanduíche por um aplicativo de celular, o lanche não chega magicamente por meio de uma materialização de dados do alimento sob o aparelho. É necessária uma conexão com a internet; padrões de dados e segurança; funcionamento da lanchonete ou restaurante; montagem do lanche; envio por meio de um entregador; e assim por diante. A invisibilidade dessa base é construída pela prática de embutir ações humanas em tecnologias que se comportam como caixas pretas, cujo funcionamento não se deve preocupar (Latour, 1999). Para perceber as relações infraestruturais invisibilizadas pelo caixapretar (blackboxing) — a criação de caixas pretas — torna-se necessário realizar uma inversão infraestrutural.

\section{INVERSÃO INFRAESTRUTURAL}

A inversão infraestrutural é um termo metodológico criado por Geoffrey C. Bowker (1994) para designar uma mudança de foco no estudo de infraestruturas da informação. Ao invés de olhar para o que está aparente, a inversão infraestrutural concentra-se nas relações invisíveis, nas explicações históricas tradicionais, nas escolhas e políticas incorporadas aos sistemas e na interação concreta entre pessoas e objetos (Star \& Ruhleder, 1994). Em uma simplificação, trata-se de um processo perceptual similar ao provocado pelo vaso de Rubin (Figura 1). Para enxergar os rostos, ou o vaso, é necessário um esforço perceptual maior, uma vez que a imagem está incompleta. 


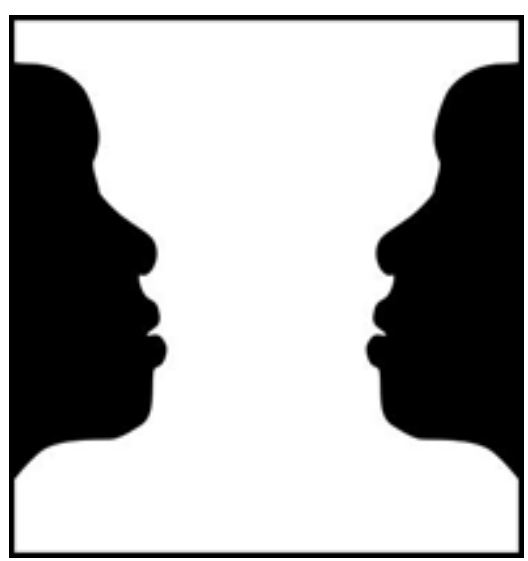

Figura 1 - vaso/rosto (os autores)

Esse esforço perceptual revela o trabalho invisível que opera e justifica as infraestruturas (Bowker, 1994). Essa descoberta da infraestrutura se expressa através de narrativas principais, que descrevem as vozes dos grupos sociais visibilizados e invisibilizados pelas infraestruturas (Star, 1999).

Apesar dos estudos sobre infraestruturas auxiliarem na compreensão das relações de trabalho, na maneira pela qual as pessoas constroem sistemas e em como são articuladas as narrativas, esses estudos são fundamentados em cosmovisões modernas, não contemplando as dimensões existenciais e ambientais de quem as compõe e de quem as constrói. Além disso, não consideram as especificidades da condição de subdesenvolvimento nos projetos existenciais coletivos e na relação com a natureza (Vieira Pinto, 2005). A aplicação de conhecimentos sociológicos e antropológicos no contexto Latino-americano requer políticas de alteridade para considerar os debates e as lutas históricas em torno de bem-estar, direitos da natureza, lógicas comunitárias e transições civilizacionais que existem neste território (Escobar, 2018; Vieira Pinto, 2005). Tornar visível o trabalho infraestrutural não nos parece suficiente. Acreditamos que é preciso também denunciar a realidade opressiva e anunciar a realidade libertadora da América Latina (Freire, 1974). Uma das práticas utilizadas pelos movimentos sociais e acadêmicos latinoamericanos para promover encontros críticos entre epistemologias do Norte e epistemologias do $\mathrm{Sul}^{5}$ é a tradução intercultural (Santos, 2018). Ao invés de explicar uma cultura para outra, a tradução intercultural visa a construção de ações conjuntas contra a dominação cultural. Propomos, então, a tradução intercultural entre o perspectivismo ameríndio do Sul e o pensamento infraestrutural do Norte como uma maneira de habilitar futuras colaborações.

\section{PERSPECTIVISMO AMERÍNDIO}

\footnotetext{
${ }^{5}$ Como epistemologias do Sul, entende-se os saberes e práticas de grupos sociais provenientes do Sul global, países colonizados e subalternizados que foram objetificados ou transformados em matéria prima para saberes dominantes, considerados os únicos válidos (ver Santos, 2018).
} 
Através de extenso trabalho de revisão bibliográfica e etnografia, o antropólogo Eduardo Batalha Viveiros de Castro (1996) identificou uma epistemologia do Sul chamada de perspectivismo ameríndio. Nessa epistemologia, são cruzadas deliberadamente as fronteiras corporais entre as espécies, adotando perspectivas "estrangeiras", perspectivas dos outros (Viveiros de Castro, 2015). É uma espécie de política cósmica, na qual diferentes visões de mundo são personificadas, inclusive de seres não-humanos (Viveiros de Castro, 2015). Para a visão de mundo ocidental, o "jogo epistemológico se chama objetivação", transformando "o que não foi objetivado" em algo "irreal e abstrato", fazendo do outro uma "coisa" (Viveiros de Castro, 2002, p. 358). Em contraposição, no perspectivismo:

“(...) conhecer é personificar, tomar o ponto de vista daquilo que deve ser conhecido - daquilo, ou, antes, daquele; pois o conhecimento xamânico visa um 'algo' que é um 'alguém', um outro sujeito ou agente" (Viveiros de Castro, 2002, p. 358).

No perspectivismo, o conhecedor é mais importante do que o conhecimento. Para os estudos de infraestruturas da informação, isso implica em uma inversão da inversão infraestrutural. Ao invés de compreender as relações entre humanos e não-humanos como um objeto/meio para realizar algo, as cosmovisões ameríndias antropomorfizam o outro. Essa diferença epistemológica entre a objetivação do ser no pensamento ocidental e a subjetivação do mundo para as cosmovisões ameríndias, se desdobra em grandes diferenças ontológicas.

Por exemplo,o conceito ocidental de ecologia foi criado para objetificar ligações entre coisas, para descrever habitats, ou identificar nichos ecológicos no ambiente natural (Levins, 1968) ou nas construções humanas (Hardesty, 1975). Já para o povo Yanomami, o que entendemos como ecologia existe por Omama, uma relação entre todos os seres vivos, incluindo os humanos e todos os outros elementos (Kopenawa \& Albert, 2019). Omama é o pai da nação Yanomami, o criador e mentor de todas as regras e costumes, incluindo entidades complexas como rios, montanhas, florestas, o céu e o sol. Trata-se de uma espécie de corpo indivisível, uma unidade:

“(...) Omama tem sido, desde o primeiro tempo, o centro das palavras que os brancos chamam de ecologia.(...) Na floresta, a ecologia somos nós, os humanos. Mas são também, tanto quanto nós, os xapiri [espíritos da floresta amazônica ou ancestrais animais], os animais, as árvores, os rios, os peixes, o céu, a chuva, o vento e o sol!" (Kopenawa \& Albert, 2019, p. 479-480).

O que definimos como natureza para os yanomamis é Urihi-a, a terra-floresta e, pelos xamãs, como Urihinari-a, uma imagem do espírito da floresta que percebe a sua própria vida (Kopenawa et al., 2009). Esta se relaciona com Hutukara, o mundo, um corpo indivisível, que "fica junto com a pedra, terra, com a areia, o rio, o mar, o sol, a chuva e o vento [...] [que] é igual a nós, [pois] ela [Hutukara] está viva" (Gomes \& Kopenawa, 2015, p. 146-147). Esta relação entre todos os seres implica também um sentido de estado-nação: "[...] é uma grande pátria, um grande governo[...]. É o verdadeiro, nosso grande governo" (Gomes \& Kopenawa, 2015, p. 147). Hutukara é a mãe da 
nação Yanomami e vai continuar existindo com ou sem os humanos, porque "ela vai até o fim do mundo" (Gomes \& Kopenawa, 2015, p. 148).

Omama, Urihi-a e Hutukara estão entrelaçadas na cosmovisão Yanomami. Uma não existe sem a outra. Quando se quebra o vínculo entre elas, surge Xawara (epidemia), ou Xawara Wakëshi (epidemia-fumaça), causada pela fumaça da queima de ouro, metais, minérios, ou a poluição que afeta tanto as pessoas quanto o céu, lugar onde moram fantasmas, trovões e diversos outros espíritos (Kopenawa, 1990). Se o céu fica muito doente, ele se despedaça e cai sobre os humanos.

Essa alteridade radical que personifica e toma o ponto de vista do outro, humano ou não-humano, representa uma alternativa à objetividade moderna, que abstrai o outro para dominá-lo. Nesse ponto, o perspectivismo ameríndio proposto por Viveiros de Castro explica como ocorre a tradução de mundo para o contexto do xamanismo Yanomami e coloca-o em patamar epistemológico equivalente a teorias modernas. Contudo, a elevação da abstração acontece ao custo da homogeneização de diversas cosmovisões. No mapeamento realizado pelo Instituto Brasileiro de Geografia e Estatística (IBGE) em 2010, disponível no sítio eletrônico da Fundação Nacional do Índio (FUNAI - funai.gov.br), a população indigena brasileira aparece composta por cerca de 817.963 mil pessoas, incluindo 305 diferentes etnias que, juntas, falam um total de 274 línguas. Muitas dessas etnias não reproduzem o padrão identificado por Viveiros de Castro. Além disso, a cultura dos povos indígenas é viva e os conceitos podem sofrer mudanças, não somente por uma política cósmica de rituais, mas também por contatos interétnicos e por questões políticas, assim como demonstra a evolução do conceito de Xarawa.

De acordo com o antropólogo francês Bruce Albert (1990), a Xawara é espontaneamente associada pelos yanomamis a uma fumaça patogênica ligada a incursões secretas (feitiçarias), lançada pelos napë (inimigos, estrangeiros, não-yanomami e brancos) nas proximidades das casas dos Yanomami (Albert, 1990, p. 163). Ao longo do tempo, o conceito de Xawara teve um novo desdobramento, incorporando a "fumaça do ouro", a "fumaça do minério", "fumaça das fábricas" e, por fim, na assimilação do conceito de "poluição" (Albert, 2002, p. 252). A extensão do campo semântico da epidemia-fumaça, "conduziu de uma interpretação epidemiológica da alteridade dos brancos a uma crítica cosmológica de sua atividade econômica", partindo de uma "metáfora tradicional da hiperpredação pela feitiçaria guerreira" à "uma tradução xamânica do efeito estufa" (Albert, 2002, p. 252). Para os Yanomami, a produção de conceitos ultrapassa os rituais xamânicos, se tornando meio de crítica social ao modelo de exploração econômica dos brancos e um alerta para o próprio povo.

Apesar de reducionista, o perspectivismo ameríndio reconhece a possibilidade de tradução e re-contextualização de conceitos dos povos originários através da exaltação das diferenças (e não das similaridades) com os conceitos modernos (Viveiros de Castro, 2019), tal como fizeram o povo Yanomami com o conceito de ecologia. Para antropólogos modernos, o autor recomenda 
um tipo de tradução intercultural (Santos, 2018) chamada equivocação controlada (Viveiros de Castro, 2004). Na equivocação controlada, realiza-se uma tradução parcial, mantendo os termos, contexto e a não-identidade entre a cosmovisão originária e a cosmovisão de quem traduz. Durante a equivocação, busca-se "que os conceitos alienígenas deformem e subvertam a caixa de ferramentas conceituais do tradutor", possibilitando assim a expressão e contexto da língua original dentro do idioma de quem traduz (Viveiros de Castro, 2004, p. 5). O tradutor deve trair a sua própria língua ao invés de trair a língua de origem. Logo, as diferenças se tornam uma condição da significação e não um impeditivo (Viveiros de Castro, 2004). Apesar de não concordamos inteiramente com a redução do perspectivismo ameríndio, procedemos à nossa análise com o método de equivocação controlada dos conceitos Yanomami relevantes para pensar a inversão infraestrutural estimulada pela pandemia COVID-19.

Os conceitos Omama, Hutukara, Urihi-a e Xawara permitem enquadrar os estudos de infraestruturas sob um viés de responsabilidade, ressaltando a dependência entre todos os seres interconectados. A partir de Omama, podemos deformar o conceito de infraestrutura e compreender que se refere a um corpo coletivo vivo (Figura 2); a partir de Hutukara, podemos compreender as infraestruturas de informação como uma infraestrutura das infraestruturas, uma relação de interdependência entre todos os seres; a partir de Urihi-a, entendemos que as infraestruturas da informação são meios de existência; e a partir de Xawara, podemos compreender a quebra de infraestruturas como uma epidemia que pode se espalhar de ser em ser vivo, transformando-se em uma pandemia, uma queda do céu que ameaça a existência de todos os seres.

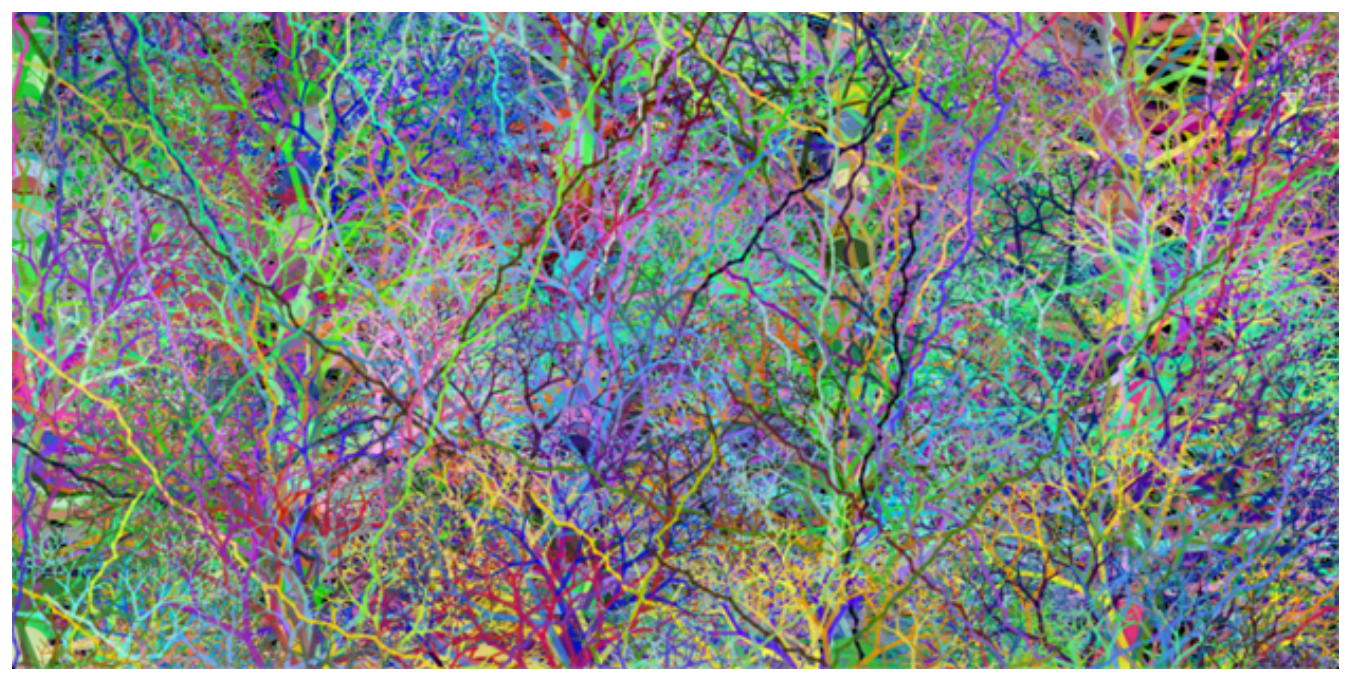

Figura 2 - Representação de infraestruturas como formas de vida coletiva que nascem, crescem, se reproduzem, adoecem e morrem (os autores, código executado em Processing).

Essa primeira deformação já revela diferenças fundamentais entre o perspectivismo ameríndio e os estudos infraestruturais. A equivocação controlada prosseguirá, no próximo tópico, através da 
reconstrução da narrativa principal do COVID-19, realizando um breve mapeamento das relações históricas e ecológicas expostas pela pandemia no Brasil.

\section{A QUEDA DO CÉU}

A pandemia COVID-19 paralisou vários setores da economia, desencadeando mudanças drásticas na vida das pessoas, tanto em atividades familiares quanto nas atividades de trabalho. Desigualdades sociais, opressões, violências domésticas e relações de trabalho antes escondidas ou evitadas se tornaram visíveis. Entraram em voga discussões sobre sistemas técnicos e sociais, as formas de projetá-los, sua manutenção, assim como uma reavaliação ampla do modo de viver moderno em sociedade (Santos, 2020). O discurso neoliberal da economia imaterial caiu por terra, deixando explícito as relações ecológicas que ligam o desenvolvimento tecnológico à dependência do sangue e suor da massa de trabalhadores (Vieira Pinto, 1962; 2005). A perda de responsabilidade sobre o ambiente, associada a esse discurso, fez adoecer o pluriverso de mundos em troca de uma busca infindável por riquezas acumuladas no universo capitalista, o que os Yanomami chamam de Xawara.

Apesar do Ministério da Saúde ter confirmado o primeiro caso do vírus no Brasil no dia 26 de fevereiro de 2020, os estados brasileiros só fizeram paralisações de atividades econômicas a partir da metade de março daquele mesmo ano. As paralisações incluíram os sistemas sociotécnicos de transporte público, entretenimento, cultura e ensino. Esta paralisação, nos diferentes setores e as recorrentes mortes em nosso contexto, romperam com vários alicerces que mantinham o céu sobre as nossas cabeças. A quebra de infraestruturas revelou a narrativa principal por trás do discurso neoliberal: um projeto político, construído pelos mais privilegiados e pensado para o fortalecimento destes, enquanto exclui os menos favorecidos.

A Xawara, espalhada pela ideologia neoliberal, deixou as infraestruturas doentes. Diversas universidades e escolas do ensino básico adotaram práticas de Educação a Distância (EAD) baseadas em infraestruturas de informação improvisadas. Os que já dispunham de acesso a essas infraestruturas foram privilegiados, enquanto os que não tinham acesso foram forçados a se adaptar rapidamente ou foram completamente excluídos das infraestruturas. Professores tiveram que aprender a ensinar remotamente, utilizando de seus próprios recursos para alcançar esse objetivo, sem remuneração extra ou treinamento adequado. Já para os estudantes, muitos não conseguiram acesso às infraestruturas, em especial os que moram em lugares isolados, tais como comunidades indígenas e quilombos, ou mesmo em lugares centrais excluídos, como favelas. Tanto estudantes como professores também enfrentam problemas relativos à falta do convívio social e pessoal, perdendo cuidados com a saúde física e mental, sua e de seus familiares.

No caso dos trabalhadores vinculados a plataformas digitais de micro-trabalho, as infraestruturas de informação personificaram as criaturas sobrenaturais que se mantinham caladas sobre o céu, até o momento em que o céu começou a cair. Os motoristas uberizados, assim como os que 
faziam entregas por meio de aplicativos, realizaram protestos e denunciaram padrões de exploração dos aplicativos que já existiam antes da pandemia mas que se tornaram ainda mais intensos com ela. Nestas manifestações, os trabalhadores relataram que a demanda de trabalho aumentou e, como consequência, ficaram mais expostos ao vírus. Os aplicativos diminuíram drasticamente os pagamentos em relação à quantidade de horas e, além de não fornecerem direitos trabalhistas, as empresas não proveram equipamentos, tanto os de trabalho, quanto de segurança, neste caso, as máscaras e produtos desinfetantes. Os ativismos e reivindicações, de motoristas e entregadores, demonstram que existem vozes historicamente ignoradas nas infraestruturas de informação do capitalismo de plataforma (Srnicek, 2017). Com as manifestações, ficou evidente para o público que a opção conveniente para uns é construída a partir da exploração inevitável de outros, obrigados a se juntar às plataformas pela falta de empregos estáveis.

Os trabalhadores que possuíam empregos estáveis, por sua vez, protestaram contra a volta antecipada ao trabalho, quando o número de casos da doença ainda não tinha começado a diminuir. Vários empresários, políticos, banqueiros, ruralistas e representantes religiosos se colocaram contra as indicações da Organização Mundial de Saúde (OMS) e de políticas públicas seguidas por outros países. Promovendo manifestações, em grande parte dentro de seus próprios carros com buzinaços, ou indo a frente do Planalto Central, com seu pequeno corpo de pessoas, exigindo que as classes mais oprimidas dispusessem de seu bem-estar para enriquecer ainda mais as empresas ou a fim de fortalecer seu projeto existencial baseado na exploração das massas (Vieira Pinto, 1962). Ainda que o governo federal tivesse ouvido suas demandas e anunciado o fim das paralisações, empresários e empresárias realizaram demissões em massa, fazendo com que milhões de famílias perdessem seu sustento.

O presidente da república Jair Messias Bolsonaro, assim como seus subalternos (família, que também assumem cargos de poder e afiliados políticos) ofereceram ao povo, como garantia de segurança no retorno ao trabalho, a distribuição gratuita de hidroxicloroquina e outros medicamentos sem comprovação científica para tratamento de COVID-19 - inclusive, sendo tais medicamentos indicados por um aplicativo desenvolvido pelo próprio Ministério da Saúde, o TrateCov. O resultado foi um desastre esperado, uma vez que o medicamento não conseguiu conter a doença e o sistema sociotécnico de saúde pública - Sistema Único de Saúde (SUS) ficou sobrecarregado, incluindo também a rede privada. Infraestruturas de sepultamento em massa tiveram que ser improvisadas em algumas cidades, aproveitando infraestruturas existentes, como o serviço de preservação de carne em frigoríficos móveis. A inversão infraestrutural obrigou diversos seres humanos a verem os corpos de seus companheiros pela perspectiva de animais criados para consumo.

Nos discursos presidenciais, o presidente minimizou o impacto da pandemia sobre os sistemas sociotécnicos, enquadrando a situação apenas na perspectiva da sua própria família ou de seu 
próprio corpo: "Pelo meu histórico de atleta, caso fosse contaminado pelo vírus, não precisaria me preocupar (...)" (Palácio do Planalto, 23 de março, 2020); "Não sou coveiro" (UOL, 20 de abril, 2020); “Tá morrendo gente? Tá! Lamento? Lamento, mas vai morrer muito, muito, mas muito mais, se a economia continuar sendo destroçada por essas medidas [medidas preventivas de distanciamento social para conter a pandemia]" (UOL, 14 de maio, 2020); "Destinamos também, a este estado maravilhoso aqui [Pará], mesmo sem comprovação científica... mais... mais de 400 mil unidades de cloroquina para o tratamento precoce da população. Eu sou a prova viva que deu certo" (UOL, 13 de agosto, 2020). Estes discursos presidenciais revelaram uma infraestrutura eugenista instalada sobre as infraestruturas públicas para manter exposta a população menos privilegiada ao vírus, em grande parte formada por indigentes, pessoas pretas e pardas, trabalhadores informais, povos indígenas e assim por diante. A política pública de saúde pode ser considerada, neste caso, uma necropolítica, uma política que se reserva o direito de decidir quem vive e quem morre (Mbembe, 2019).

A violência do discurso governamental se reproduziu nas infraestruturas de informação oficiais e não-oficiais, tais como redes sociais, boca-a-boca e discursos religiosos. $\mathrm{O}$ agravamento da violência contra as pessoas socialmente vulneráveis, durante a pandemia pode ser considerado consequência da enfermidade dessas infraestruturas (Santos, 2020). Por não terem como se refugiar em outros lugares e serem obrigadas a conviver confinadas em suas casas, muitas mulheres, crianças e idosos sofreram abusos e maus tratos. Os índices de feminicídio cresceram drasticamente, como também diminuíram o número de registros oficiais de casos de lesão corporal dolosa. Parte deste problema está na dificuldades dos agredidos e das agredidas realizarem denúncias, por estarem com os agressores por perto.

Apesar de existirem esforços das infraestruturas de informação da mídia para conter a desinformação associada ao combate à pandemia, a cobertura sobre o Covid-19 ofuscou os desastres ambientais que já vinham ocorrendo em parques nacionais, reservas ambientais e terras indígenas. Segundo a nota técnica publicada pelo Observatório de Clima e Saúde, da Fundação Oswaldo Cruz (2020), também conhecida como Fiocruz, a grande ocorrência de queimadas, que alcançaram números recordes no ano de 2020, aliada à baixa umidade na região da Amazônia Legal e no Pantanal, agravaram o impacto da epidemia de Covid-19 em diversas regiões do país (Fiocruz, 2020). O material particulado e gases tóxicos gerados pelas queimadas da biomassa de tais florestas e matas, atingiram longas distâncias, também afetando regiões Norte e Centro-Oeste do país, bem como populações ribeirinhas, quilombolas e indígenas a centenas de quilômetros dos focos de incêndio (Fiocruz, 2020). 
Tal como a xawara é uma fumaça com fatores patogênicos, podemos traçar um paralelo com a infodemia ${ }^{6}$ e compreendê-la como uma fumaça digital que adoece as infraestruturas de informação e, consequentemente, o estado de consciência das pessoas, dificultando o discernimento entre o que faz parte da realidade concreta e o que é mentira. A principal causa de tal fumaça é referente à quantidade massiva de notícias falsas (fake news) que influenciaram diretamente na qualidade de vida das pessoas e no entendimento sobre a realidade que convivem. Essa fumaça digital realiza uma mudança no estado de consciência da população, camuflando as infraestruturas que foram reveladas durante a pandemia, banalizando a mortalidade da doença e os problemas económicos-sociais que as pessoas estão passando. Muitas das relações históricas e ecológicas que haviam se tornado visíveis foram rapidamente encobertas pela fumaça digital, dificultando a organização de ações coordenadas e mudança nos projetos existenciais coletivos em função da pandemia.

\section{DISCUSSÕES}

Quando compreendidos através do conceito de Omama, os projetos existenciais modernos que se baseiam na exploração do valor da vida ficam comprometidos pelo extrativismo (Acosta \& Brand, 2019) e pela necropolítica (Mbembe, 2019). As pessoas atuam para a construção destas infraestruturas, ao mesmo tempo em que elas atuam sobre as pessoas. A tecnologia não se desenvolve sem pessoas (Vieira Pinto, 2005). Assim como o conceito de infraestruturas descreve a relação entre diferentes atores para a construção e funcionamento das coisas, Omama descreve esta interconexão sob um viés de responsabilidade (Kopenawa \& Albert, 2019). A inversão infraestrutural de Omama revela a vida como um todo, incluindo mais relações além de trabalho, incluindo mais seres vivos além dos humanos.

Além disso, se os estudos de infraestrutura levarem Hutukara em consideração, veremos nosso mundo como um todo e não mais como uma mera fonte de recursos. Assim, somos pessoas coletivas, todos diferentes, mas formamos juntos pequenas constelações (Krenak, 2019). Não estamos no mundo, nós somos o mundo. Se destruímos Omama, o céu cai sobre nós. O perspectivismo ameríndio (Viveiros de Castro, 2015) nos dá algumas pistas para pensarmos o projeto de infraestruturas a partir da alteridade radical. O projeto, que ocorre da infraestrutura para o mundo, pode ser considerado responsável, mesmo que não intencionalmente, pela disseminação da doença, apesar de ser também o locus da esperança para a mudança de visões de mundo (Lagrou, 2020). Sendo assim, podemos considerar que a fumaça digital é sinal de que há algo queimando nas infraestruturas da informação. Além do trabalho explorado invisível, existe um trabalho alienado invisível, daqueles que espalham fumaça digital, que logo se torna visível, mas opaca. Isso só é possível porque tais infraestruturas ainda oferecem poucas funcionalidades

${ }^{6}$ Conforme a Organização Pan-Americana da Saúde (OPAS), a infodemia pode ser compreendida como "um excesso de informações, algumas precisas e outras não, que tornam difícil encontrar fontes idôneas e orientações confiáveis quando se precisa" (OPAS, 2020). 
para separar o que é informação do que é desinformação, um recurso crucial para curar a infodemia. No projeto de infraestruturas de informação, encontra-se, portanto, a possibilidade de desconstruir e reconstruir visões de mundo que contribuam para uma consciência de si, do mundo e das consequências de atos repetidos diariamente (Vieira Pinto, 2005).

Podemos concluir com este estudo que as cosmovisões ameríndias, tal como o xamanismo Yanomami, além de permitir um olhar crítico a respeito de questões ambientais, técnicas e sociais, podem inspirar projetos de infraestruturas da informação com maior responsabilidade pelas suas consequências a longo prazo. Da mesma forma que Omama possui vida, cria costumes e é a relação entre todos os seres; e Hutukara, o grande governo e o corpo indivisível, que também envolve humanos e não-humanos, as infraestruturas também vivem, são formadas por pessoas, animais e artefatos, dão suporte à diversas regras de funcionamento das coisas e possuem relações interdependentes. Quando as pessoas estão doentes, as infraestruturas também ficam doentes e vice-versa.

\section{CONSIDERAÇÕES FINAIS}

Durante o texto, procuramos definir os conceitos de infraestrutura e infraestrutura de informação, assim como da implicação metodológica dos termos, a inversão infraestrutural. Em seguida, contrapomos tal pensamento infraestrutural com o perspectivismo ameríndio e a filosofia Yanomami, deformando a base conceitual da inversão infraestrutural, a partir da equivocação controlada dos conceitos de Omama, Hutukara, Urihi-a e Xawara. Utilizamos essa equivocação controlada para contextualizar a pandemia COVID-19 por um viés de responsabilidade. Também desenvolvemos o conceito de fumaça digital para compreender a infodemia e seus impactos sobre a consciência de si.

Os estudos sobre infraestruturas se demonstraram mais uma vez relevantes para compreendermos a materialidade das relações de trabalho; dimensões de poder; diferentes realidades sociais; e os apagamentos produzidos pela construção de sistemas técnicos-sociais. Porém, nesses estudos, ainda existe uma lacuna sobre as dimensões existenciais e ecológicas na construção de projetos de mundo. A objetivação da relação entre os humanos e não-humanos envolvidos nos contextos sócio-técnicos pela técnica da inversão infraestrutural não contempla a pluriversidade que diferentes culturas possuem de compreender e criar mundos. Provavelmente, por esse motivo, ainda não existem pesquisas que contemplem epistemologias do Sul nos estudos de infraestrutura. Essas epistemologias, oferecem "outros saberes e outras práticas de criação e transmissão do conhecimento que resultam de práticas sociais de resistência e luta contra a dominação" (Santos, 2018, p. 248).

Apesar das limitações do perspectivismo ameríndio e dos estudos de infraestruturas, sua aproximação aponta caminhos para possíveis métodos de tradução intercultural nos estudos de infraestruturas e em CTS. Poderíamos arriscar neste trabalho em propor (assumindo todos os 
riscos de erros esperados) de um método de equivocação infraestrutural: ao mesmo tempo em que é realizada a mudança de foco, observando as relações invisíveis em momentos que as infraestruturas param de funcionar, ou prestando atenção a detalhes geralmente despercebidos, o pesquisador ou pesquisadora, deforma a caixa de ferramentas conceituais utilizadas na pesquisa a partir da cosmovisão estudada. Esse método ainda não se encontra definido e carece de testes mais amplos.

Além de desenvolver métodos de tradução intercultural, sugerimos que, em estudos futuros, sejam confrontadas diferentes cosmovisões nos estudos de infraestrutura e em CTS de um modo geral. Também acreditamos que seria interessante um estudo mais aprofundado sobre as benesses e limites de utilizar o perspectivismo ameríndio no planejamento e execução de projetos existenciais de longo prazo (Escobar, 2018; Vieira Pinto, 2005), que incluam infraestruturas de informação como modo de vida.

\section{AGRADECIMENTOS}

Agradecemos à Coordenação de Aperfeiçoamento de Pessoal de Nível Superior (CAPES) pelo financiamento de bolsa de estudos no nível de mestrado para o primeiro autor - código de financiamento 001 .

Agradecemos também pelas contribuições, através de comentários realizados, por Bianca Caroline Orsso, Juliana Ferreira (Zzui), João Conrado Dembiski, Rafaela Angelon, Rodrigo Freese Gonzatto e das(os) revisoras(es) anônimas(os) que avaliaram o artigo. Agradecemos ao professor Luiz Ernesto Merkle por sugerir um aprofundamento na bibliografia ameríndia para realizarmos o trabalho. Também agradecemos a Bibiana Serpa, pelo acolhimento e atenciosidade na editoração da revista.

\section{REFERÊNCIAS}

Acosta, A., \& Brand, U. (2019). Pós-extrativismo e decrescimento: Saídas do labirinto capitalista. Editora Elefante.

Albert, B. (1990). A fumaça do metal: História e representação do contato entre os Yanomami. Anuário Antropológico, 14(1), 151-189.

Albert, B. (2002). O ouro canibal e a queda do céu: Uma crítica xamânica da economia política da natureza (Yanomami). In B. Albert \& A. R. Ramos (Orgs.), Pacificando o branco: Cosmologias do contato no Norte-Amazônico (1a. ed, p. 239-270). Editora UNESP : Imprensa Oficial SP : IRD, Institut de recherche pour le développemnent.

Bowker, G. (1994). Information mythology: The world of/as information. Information acumen: The understanding and use of knowledge in modern business, 231-247. 
Bowker, G. C., Baker, K., Millerand, F., \& Ribes, D. (2009). Toward information infrastructure studies: Ways of knowing in a networked environment. In International handbook of internet research (p. 97-117). Springer.

Carson, R. (1962). Silent spring ( $1^{\circ}$ ed). Houghton Mifflin Company.

Cutcliffe, S. (2003). La emergencia de CTS como campo académico. In Ideas, máquinas y valores: Los estudios de ciencia, tecnología y sociedad (p. 07-24). Universidade Nacional Autônoma do México.

Escobar, A. (2016a). Autonomía y diseño: La realización de lo comunal. Editorial Universidad del Cauca.

Escobar, A. (2016b). Cosmo/visiones del Pacífico y sus implicaciones socioambientales: Elementos para un diálogo de visiones. Foro Visión pacífico.

Escobar, A. (2016c). Thinking-feeling with the Earth: Territorial Struggles and the Ontological Dimension of the Epistemologies of the South. AIBR, Revista de Antropología Iberoamericana, 11(1), 11-32. https://doi.org/10.11156/aibr.110102e

Escobar, A. (2018). Designs for the pluriverse: Radical interdependence, autonomy, and the making of worlds. Duke University Press.

Fiocruz. (2020). Covid-19 e queimadas na Amazônia Legal e no Pantanal: aspectos cumulativos. Nota Técnica. https://portal.fiocruz.br/sites/portal.fiocruz.br/files/documentos/nota_queimadascovid_nov2020.p df

Freire, P. (1974). Pedagogia do oprimido ( $1^{\circ}$ ed). Paz e Terra.

Gomes, A. M. R., \& Kopenawa, D. (2015). O Cosmo segundo os Yanomami: Hutukara e urihi. Revista da Universidade Federal de Minas Gerais, 22(1.2), 142-159. https://doi.org/10.35699/2316-770X.2015.2743

Hardesty, D. L. (1975). The Niche Concept: Suggestions for Its Use in Human Ecology. Human Ecology, 3(2), 71-85.

Kling, Rob; and Walt Scacchi (1982). The web of computing: Computing technology as social organization. Advances in Computers. Vol. 21, pp. 1-90.

Kopenawa, D. (1990). Xawara: O ouro canibal e a queda do céu. Entrevista a Bruce Albert.

Kopenawa, D., \& Albert, B. (2019). A queda do céu: Palavras de um xamã yanomami. Editora Companhia das Letras. 
Kopenawa, D., Albert, B., Milliken, W., \& Gomez, G. G. (2009). Urihi A. In Urihi A: a terra-floresta Yanomami (p. 8-9). ISA ; IRD Institut de recherche pour le développement.

Krenak, A. (2019). Ideias para adiar o fim do mundo. Editora Companhia das Letras.

Lagrou, E. (2020). Nisun: A vingança do povo morcego e o que ele pode nos ensinar sobre o novo coronavírus. http://ds.saudeindigena.icict.fiocruz.br/handle/bvs/1963

Latour, B. (1999). Pandora's hope: Essays on the reality of science studies. Harvard university press.

Latour, B. (2020). Imaginar gestos que barrem o retorno da produção pré-crise | N-1 Edições (D. Danowski \& E. V. de Castro, Trads.). AOC-Media, domingo, 29. N-1 Edições.

Levins, R. (1968). Evolution in changing environments: Some theoretical explorations. Princeton University Press.

Mbembe, A. (2019). Necropolitics. Duke University Press.

Organização Pan-Americana da Saúde (OPAS). Organização Mundial da Saúde (OMS). Repositório Institucional para Troca de Informações (Iris). Fichas Informativas COVID-19: entenda a infodemia e a desinformação na luta contra a COVID-19; 2020. https://iris.paho.org/handle/10665.2/52054?locale-attribute=pt

Palácio do Planalto. (2020, março 24). Pronunciamento do presidente da República, Jair Bolsonaro [arquivo de vídeo]. YouTube. https://www.youtube.com/watch?v=Vl_DYb-XaAE\&ab_channel=Planalto

Santos, B. de S. (2007). Para além do Pensamento Abissal: Das linhas globais a uma ecologia de saberes. Revista Crítica de Ciências Sociais, 78, 3-46. https://doi.org/10.4000/rccs.753

Santos, B. D. S. (2018). The End of the Cognitive Empire: The Coming of Age of Epistemologies of the South. Duke University Press.

Santos, B. de S. (2020). A Cruel Pedagogia do Vírus. Almedina. https://estudogeral.sib.uc.pt/handle/10316/89207

Srnicek, N. (2017). Platform capitalism. John Wiley \& Sons.

Star, S. L. (1999). The ethnography of infrastructure. American behavioral scientist, 43(3), 377-391.

Star, S. L., \& Bowker, G. C. (1995). Work and infrastructure. Communications of the ACM, 38(9), 41.

Star, S. L., \& Ruhleder, K. (1996). Steps toward an ecology of infrastructure: Design and access for large information spaces. Information systems research, 7(1), 111-134. 
Star, S. L., \& Ruhleder, K. (1994). Steps Towards an Ecology of Infrastructure: Complex Problems in digital access for large-scale collaborative systems. CSCW 94 Proceedings of ACM 1994 Conference on Computer Supported Cooperative Work, 253-264.

UOL. (2020, abril 20). Bolsonaro sobre o número de mortos por COVID-19: "Não sou coveiro" [arquivo de vídeo]. YouTube. https://www.youtube.com/watch?v=aIpUbYjjdn0\&ab_channel=UOL

UOL. (2020, maio 14). Bolsonaro: “Tá morrendo gente? Está. Lamento! [arquivo de vídeo]. YouTube. https://www.youtube.com/watch?v=KiULxdC8hB8\&ab_channel=UOL

UOL. (2020, agosto 13). Cloroquina: Bolsonaro diz que marca de 100 mil mortes por covid-19 seria evitada com $\quad 0 \quad$ medicamento. https://www.youtube.com/watch?v=nR-hZkR3sLI\&ab_channel=UOL

Vieira Pinto, Álvaro. (1962). Por que os ricos não fazem greve? (Vol. 4). Editora Civilização Brasileira.

Vieira Pinto, Álvaro. (2005). O conceito de tecnologia. Editora Contraponto: Rio de Janeiro.

Viveiros de Castro, E. B. (1996). Os pronomes cosmológicos e o perspectivismo ameríndio. Mana, 2(2), 115-144. https://doi.org/10.1590/S0104-93131996000200005

Viveiros de Castro, E. B. (2002). Perspectvismo e multi naturalismo na América indígena. In A inconstância da alma selvagem e outros ensaios de antropologia. Cosac \& Naify.

Viveiros de Castro, E. B. (2004). Perspectival anthropology and the method of controlled equivocation. Tipití: Journal of the Society for the Anthropology of Lowland South America, 2(1). https://digitalcommons.trinity.edu/tipiti/vol2/iss1/1

Viveiros de Castro, E. B. (2015). Metafísicas canibais: Elementos para uma antropologia pós-estrutural. São Paulo: Cosac Naify.

Viveiros de Castro, E. B. (2019). On Models and Examples: Engineers and Bricoleurs in the Anthropocene. Current Anthropology, 60(S20), S296-S308. https://doi.org/10.1086/702787 